\title{
INFLAMMATORY PSEUDOTUMOUR OF THE LARYNX: A CASE REPORT
}

Jayesh K. Thampi ${ }^{1}$, V. R. Rajendran², P. Rajan³, Gomathy Subramaniam4, Noufal Perumpalath ${ }^{5}$

\section{HOW TO CITE THIS ARTICLE:}

Jayesh K. Thampi, V. R. Rajendran, P. Rajan, Gomathy Subramaniam, Noufal Perumpalath. "Inflammatory Pseudotumour of the Larynx: A Case Report". Journal of Evolution of Medical and Dental Sciences 2015; Vol. 4, Issue 47, June 11; Page: 8220-8223, DOI: 10.14260/jemds/2015/1190

INTRODUCTION: Inflammatory Pseudotumour (IPT) is a benign proliferation of tissue but has a destructive potential of the affected area. It is also called Inflammatory Myofibroblastic tumour (IMT). Initially the tumour was reported in the lung but later on reported in other areas like abdomen, orbit etc. IPT of the larynx is a rare involvement.

Pathogenesis of inflammatory Pseudotumour remains controversial and treatment is under standardised. Pseudotumours of Larynx are reported more common in boys around the age of 10 yrs.

We report a case of IPT in a 11 yrs. old girl, who underwent surgery, with 1yr follow up.

CASE REPORT: An 11yrs. old female child presented with breathing difficulty of 2 weeks duration; inspiratory stridor and change in voice of recent onset. No other significant past, personal or family history.

Patient consulted in the ENT department and as a part of the investigations, a plain lateral radiograph of neck was taken.

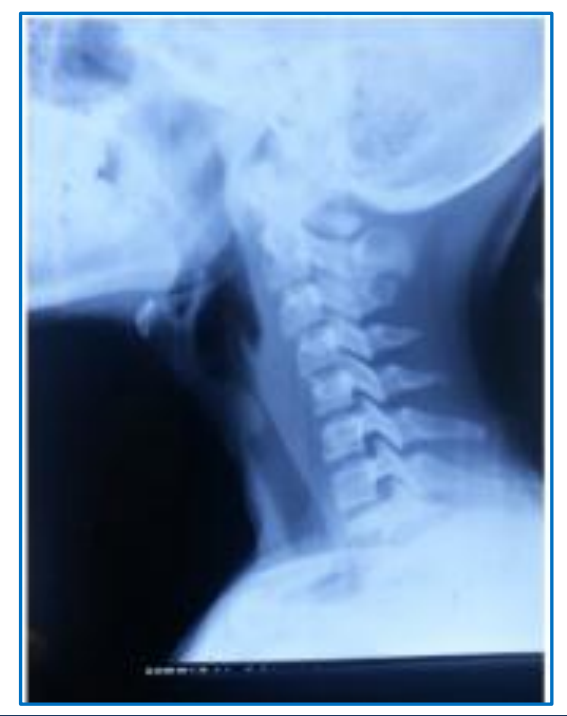

\section{Fig. 1: Plain lateral Radiograph of Neck}

Plain lateral radiograph of neck revealed a radiopaque soft tissue mass in the subglottic location of larynx, projecting into the lumen with compromise of the laryngeal lumen. No calcification was seen.

Videolaryngoscopy was done showed a smooth reddish mass in the subglottis obstructing $80 \%$ of the airway-possibility of haemangioma was suggested.

For further characterisation of the lesion the child was send for CECT to our department in May 2014. 


\section{CASE REPORT}

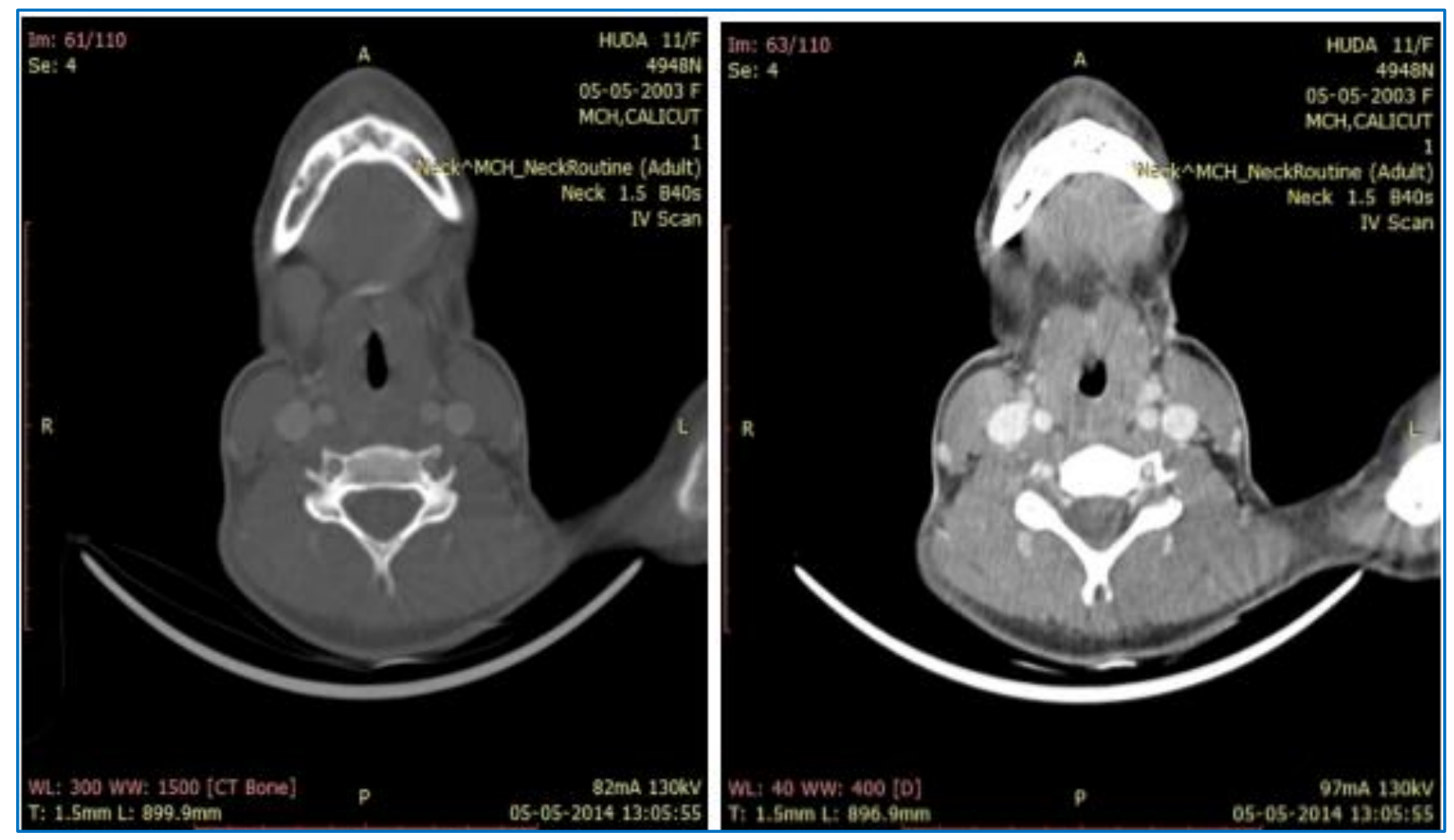

Fig. 2: Plain and Contrast Ct Section of Larynx Below the Vocal Cord

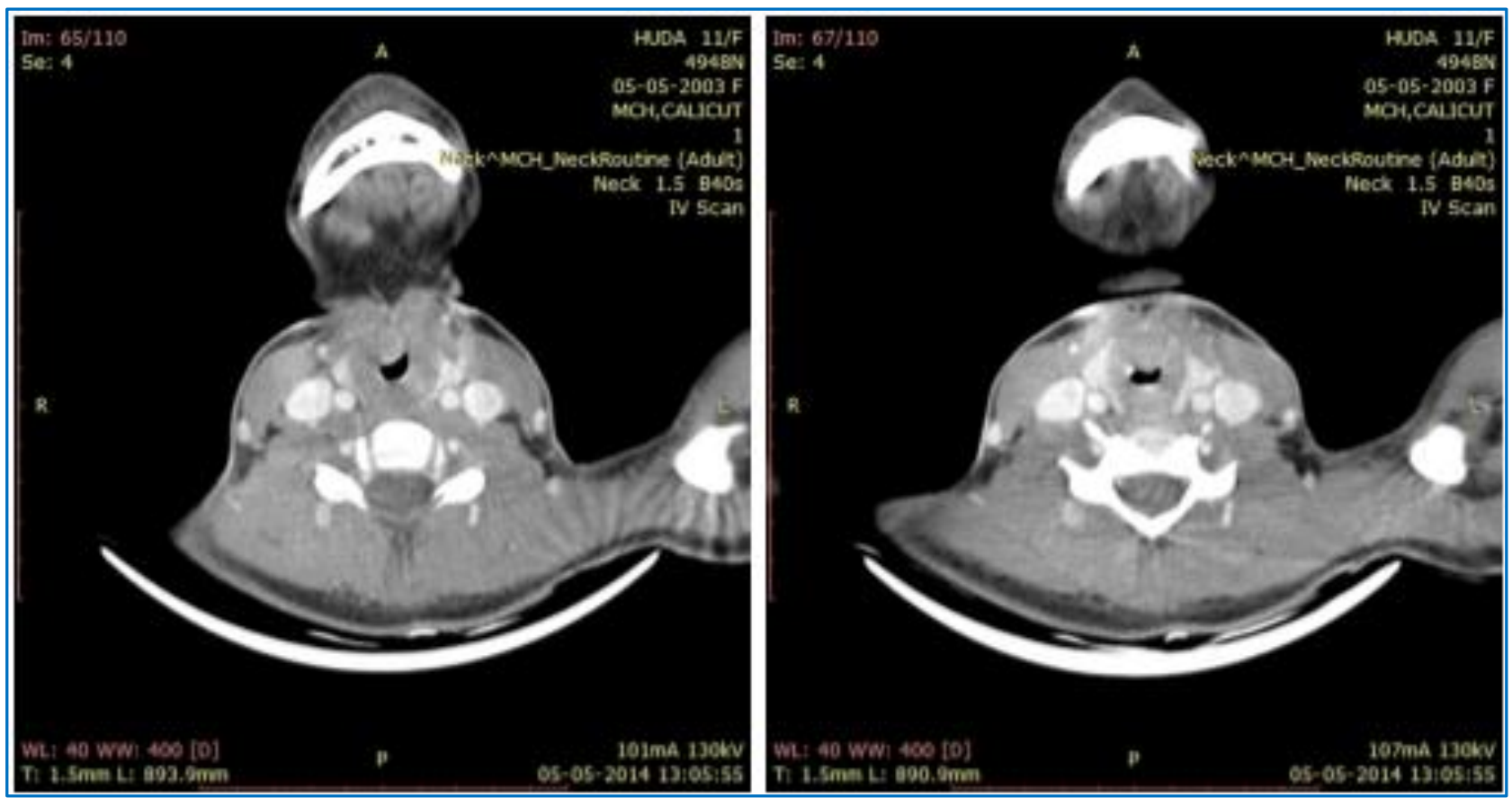

Fig. 3: Plain and Contrast section of larynx at lower Subglottis

Plain and contrastaxial section of Nasopharynx revealed a minimally enhancing soft tissue density lesion encircling the hypopharynx and larynx. Anteriorly the lesion is projecting into the 


\section{CASE REPORT}

laryngeallumen in the subglottic locationwith subglottic airway narrowing. Craniocaudally the lesion is extending from the level of $\mathrm{C} 3$ to $\mathrm{C} 6$ for a length of $7 \mathrm{cms}$. Both aryepiglotic folds were thickened. By CECT a possibility of Lymphoma was given with a differentials of Inflammatory Pseudo tumour or Hemangioma.

Child underwent traceostomy with endoscopic laser excision of the mass in May 2014 and the specimen was send for histopathology.

HPR with IHC was reported as inflammatory Pseudotumour.

DISCUSSION: Inflammatory Pseudo tumour (IPT) are usually diagnosed by histopathology and is considered when an inflammatorymass have inconclusive finding. Awareness of IPT developing in the head and neck region should be there.1,2 The diagnosis is by ruling out other causes. IPT can develop abruptly or as achronic process.

IPT is usually seenin younger patients which appear as solid mesenchymal tumors occuring as solitary mass. ${ }^{1}$ Lymphoplasmacytic infitration occurs into a mass that develop from well defferentiated myofibroblasts. IPT can develop anywhere in the body, lung being the most predominant site and larynx is a rare site. ${ }^{3,4}$ It is a fleshy well differentiated tumourand is hard to firm in consistancyon palpation.

Radiologically, IPTappearence is highly variable and non specific due to high fibrous content and cellular infiltration. On USG, the lesion can be well defined or ill defined, hyper or hypoechoic mass, ${ }^{5}$ and will show increased vascularity on colour or power doppler.

On CT scan, IPT is a well defined or ill defined lesion with low, equal or high attenuation compaired to adjacent soft tissue.5,6 IPT will show homogeneous or heterogeneous enhancement on post contrast study. Often there is a delayed enhancement of the lesion due toabundance of the fibrous tissue. Imaging charecters of the lesion vary from person to person. Tracheobroncheal and laryngeal IPT can present as a heterogeneous lobulated or exophytic endoluminal mass. Calcification may be present occasionally. Cases reported are more common in boys around the age of 10 yrs. $^{7}$

Treatment is long term corticosteroids and open or endoscopic surgery is required if obstuctive symtoms develop. ${ }^{8}$ Local recurrence have been reported. Potensial malignant transformaion is very rare. Overall prognosis is very good and favourable.

CONCLUSION: Inflammatory Pseudotumour of the larynx is very rare but carries a good prognosis even though local recurrence has been reported. It simulates malignant tumours like sarcomas. Radiologically it is non specific, but should be aware of this entity as a diagnostic consideration. IHC provides a defintive diagnosis. Management is with high dose steroids. Surgery is considered when obstructive symtom develops.

\section{REFERENCES:}

1. Sirvent N, Coindre JM, Pedeutour F. Tumeurs myofiroblastiques inflammatories. Ann Pathol. 2002; 22: 453-460.

2. Gnepp DR, ed. Diagnostic Surgical Pathology of Head and Neck. WB Saunders Company. New York, 2001. Non squamous Pathology of larynx, hypopharynx ans trachea: Bandwein MS, Kapadia SB, Gnepp DR. 2001; pp 239-323.

3. Dehner LP. The enigmatic inflammatory Pseudotumours: the current state of our understanding or misunderstanding. J Pathol. 2000; 277-279. 


\section{CASE REPORT}

4. Weing BM, Devaney K, Bisceglia M. Inflammatory myofibroblastic tumour of larynx. Cancer 1995; 76: 2217-2229.

5. Lim JH, Lee JH. Inflammatory Pseudo tumour of the liver: ultrasound and CT features. Clin Imaging 1995; 19: 43-46.

6. Keleskis NL, Warshauer DM, Semelka RC, Eisenberg LB, Woosley JT. Inflammatory Pseudo tumour of liver: appearenceon contrast enhanced helical CT and dynamic MR images. J Magn Reson Imaging 1995; 5: 551-553.

7. Fabre D, Fadel E, Singal S, et al. Complete resection of pulmonary inflammatory pseudotumours has exellent long term prognosis. J Thorac Cardiovasc Surg 2009; 137: 435-440.

8. Chaturvedi P, Rodirgues G, Sanghvi VD. Pseudomalignant laryngeal nodule. Histopatholog 1999;34:272-273.

\section{AUTHORS:}

1. Jayesh K. Thampi

2. V. R. Rajendran

3. P. Rajan

4. Gomathy Subramaniam

5. Noufal Perumpalath

\section{PARTICULARS OF CONTRIBUTORS:}

1. Junior Resident, Department of Radiodiagnosis, Government Medical College, Kozhikode.

2. Professor \& HOD, Department of Radiodiagnosis, Government Medical College, Kozhikode.

3. Professor, Department of Radiodiagnosis, Government Medical College, Kozhikode.

FINANCIAL OR OTHER COMPETING INTERESTS: None
4. Additional Professor, Department of Radiodiagnosis, Government Medical College, Kozhikode.

5. Associate Professor, Department of Radiodiagnosis, Government Medical College, Kozhikode.

\section{NAME ADDRESS EMAIL ID OF THE CORRESPONDING AUTHOR:}

Dr. Jayesh K. Thampi, Junior Resident, Department of Radiodiagnosis, Govt. Medical College, Kozhikode. E-mail:drjayeshkthampi@gmail.com

Date of Submission: 11/05/2015.

Date of Peer Review: 12/05/2015.

Date of Acceptance: 04/06/2015.

Date of Publishing: 11/06/2015. 